\title{
Weight Status, Physical Fitness, and Health-Related Quality of Life among Chinese Adolescents: A Cross-Sectional Study
}

\author{
Xiangren Yi ${ }^{1, * \mathbb{D}}$, You Fu ${ }^{2}$, Ryan Burns ${ }^{3}$ and Meng Ding ${ }^{4}$ \\ 1 Department of Sport and Health, School of Physical Education, Shandong University, Jinan 250061, China \\ 2 School of Community Health Sciences, University of Nevada, Reno 1664 N. Virginia Street, Reno, \\ NV 89557, USA \\ 3 Department of Health, Kinesiology, and Recreation, University of Utah, 6951 Wellwood Road, 1Y Midvale, \\ Salt Lake City, UT 84047, USA \\ 4 School of Physical Education, Shandong Normal University, Jinan 250061, China \\ * Correspondence: xrenyi@sdu.edu.cn
}

Received: 13 April 2019; Accepted: 24 June 2019; Published: 27 June 2019

check for updates

\begin{abstract}
Purpose: The impact of physical fitness (PF) on adolescents' health-related quality of life (HRQOL) is an important health issue in China. The purpose of this study was to identify whether body mass index (BMI), cardiorespiratory fitness (CRF), and musculoskeletal fitness (MSF) influences HRQOL among Chinese adolescents. Method: The participants were 10,007 students (boys $=5276,14.14$ years \pm 1.79 ; girls $=4829,14.22$ years \pm 1.81 ) who were randomly selected from 30 secondary schools in Shandong, China. BMI, CRF, MSF, and HRQOL were measured and analyzed using ANCOVA and multiple regression. Results: BMI and physical fitness variables were partially associated with HRQOL in Chinese adolescents. ANCOVA showed a significant difference among BMI categories in terms of physical sense (PS), living convenience, and self-satisfaction (SS) for boys, but this difference was only seen with social activity opportunity (SAO) for girls. Multiple regression found that BMI was significantly associated with SAO. For boys, CRF was associated with the teacher and student relationship and SS, whereas MSF was only associated with PS. For girls, CRF was significantly linked with the parent and children relationship, learning capacity, and attitudes and self-perception (S-P), while MSF was associated with S-P. Conclusion: Enforcing physical activity and enhancing PF will be a crucial pathway in improving adolescents' HRQOL in China.
\end{abstract}

Keywords: cardiorespiratory fitness; musculoskeletal fitness; obesity; health outcomes

\section{Introduction}

The high prevalence of overweightness and obesity among children and adolescents has been a large public health concern for the past three decades in China. A national survey on Students' Physical Fitness and Health in 2010 reported that the obesity rate of urban boys, urban girls, countryside boys, and countryside girls (7-22 years) were 13.33\%, 5.64\%, 7.83\%, and 3.78\% respectively. The overweight rate of urban boys, urban girls, countryside boys, and countryside girls (7-22 years) were 14.81\%, 9.92\%, $10.79 \%$, and $8.03 \%$, respectively, which have increased by $1.94 \%, 0.63 \%, 2.76 \%$, and $1.15 \%$, respectively, since 2005 [1]. The Nutrition and Chronic Disease Status of Chinese Residents (2015) also revealed that $9.6 \%$ of the population is obese and $6.4 \%$ can be classified as overweight among 6-17 year-old Chinese children and adolescents, increasing by $5.1 \%$ and $4.3 \%$, respectively, since 2002 [2]. Relative to developed countries, China's prevalence of overweightness and obesity is relatively low, but this nevertheless has progressively increased over the past decades. 
The rising prevalence of overweightness and obesity has correlated with a concomitant decrease in cardiorespiratory fitness (CRF) and musculoskeletal fitness (MSF), which may ultimately attenuate health-related quality of life (HRQOL) [3,4]. It has been documented that HRQOL is inversely associated with weight gain and the risk of overweightness and obesity in children and adolescents [5]. Previous studies have identified factors that may influence HRQOL and analyzed the association between overweightness and obesity and HRQOL. For instance, literature indicated that overweightness and obesity impairs HRQOL in children, especially those in the greatest compromised physical and social dimensions [6-8] and those with emotional or mental issues and/or self-esteem and behavioral problems $[7,9,10]$. This adds concern regarding the impact of obesity-related complications and comorbidity on self-esteem and HRQOL [11].

Specifically, Cameron and colleagues found that a lower HROQL may be a predictor, particularly related to psychosocial well-being, indicating a bi-directional association between obesity and HROQL [12]. Conversely, a recent study showed that overweightness and obesity are not significantly associated with HROQL or socio-economic circumstances; socio-cultural factors should be considered to help elucidate such relationships [13]. The impact of overweightness and obesity on HRQOL may differ among cultures [14], ages [15,16], genders [15,17], incomes [18,19], lifestyles, and ethnicities [20].

Extensive literature has revealed that CRF and MSF are significantly associated with serious health consequences, such as cardiovascular disease (CVD), diabetes, and various cancers [21-24], independently predicting a higher threat of CVD and mortality across various ages. Higher levels of physical fitness have been shown to be associated with higher levels of HRQOL in older adults and chronically diseased populations [25-27].

Recognized as one of the most important health markers, excellent physical fitness in adolescence yields more positive health outcomes $[28,29]$ and highlights the demand to reinforce physical activity in educational monitoring systems.

Although some studies have examined the relationship between CRF and HRQOL [30,31] and the relationship between overweightness and obesity and cardiorespiratory fitness in children and adolescents [29], only two studies with a small sample size have examined kindergarteners' perceptions related to quality of life across different weight statuses in Hong Kong [32] and the influence of youth overweightness and obesity on quality of life in mainland China [33]. Little is known about the relationship between physical fitness, BMI, and HRQOL as they interact among Chinese adolescents. Therefore, the hypothesis of the present study is that the weight status and physical fitness influence HRQOL. The purpose of this study was to examine the associations among CRF, MSF, and BMI on HRQOL in Chinese adolescents and to identify whether HRQOL is statistically different among BMI, $\mathrm{CRF}$, and MSF categories. This study further explores the association of youth overweightness/obesity with HRQL, self-esteem, and bullying, as well as the association of physical fitness with physical, emotional, and social health and functioning. Knowledge about these relationships may facilitate the development of specific, individually tailored physical activities in a more appropriate manner.

\section{Materials and Methods}

\subsection{Study Setting and Participants}

Using cross-sectional research design, the present study was conducted during the 2016 to 2017 academic year in Shandong Province, China. The province comprises [25] 17 regions with different geographical and demographic characteristics. The participants were recruited from 30 secondary schools (20 middle schools and 10 high schools) in 10 regions. In each region, one urban middle school, one rural middle school, and one urban high school were randomly selected with the purpose of ensuring geographical and cultural diversity. Schools with an enrollment below 300 students were excluded in this study. Initial participants consisted of 10,680 students (aged 12-18 years). Prior to data analysis, 673 students were excluded due to the absence on one of the physical fitness tests. The final participants were 10,007 students, including 5210 boys (52.1\%; $14.14 \pm 1.79$ years) and 4797 girls 
( $47.9 \% ; 14.22 \pm 1.81$ years). The research was approved by the ethical committees of Shandong University, China.

\subsection{Procedure}

There were 10 superintendents in each region who supervised the evaluators in the schools. A total of 60 evaluators were recruited from middle and high school physical education teachers who had experiences in the National Student Fitness Test Program and adolescent physical fitness evaluation. All evaluators were trained with a testing manual illustrating all the test guidelines, procedures and protocols. In addition, to standardize and homogenize the method of assessment and quality control, all evaluators completed two seminars in order to enhance intra- and inter-tester reliability. All evaluators organized students to measure physical fitness and guided students to answer online questionnaires. Six graduate students operated computers to collect online survey data from each school.

Evaluators administered all tests following standard operating procedures. The participants completed a standardized form, which included socio-demographic data such as region, school, age, gender, date of birth, grade, and ethnicity.

\subsection{Measures}

BMI: Weights and heights of barefooted students in light clothing were measured with a digital electronic weighing scale (HW-VB900, IEJIA, China) and recorded to the nearest 0.1 kilogram. BMI was computed by utilizing weight divided by the square of students' height (BMI = weight $(\mathrm{kg}) / \mathrm{height}$ $(\mathrm{m})^{2}$ ). Participants were categorized into obese, overweight, normal weight, and underweight based on the international BMI cutoff values.

Physical fitness: Physical fitness was assessed employing National Students' Physical Fitness and Health 2014 (NSPFH 2014) [34], which contained five tests that gauged different components of fitness: BMI, sit and reach (flexibility), standing-long jump (explosive strength), sit-ups for girls (abdominal strength and endurance), pull ups for boys (upper body strength and endurance), and a $1000 \mathrm{~m}$ run for boys or $800 \mathrm{~m}$ run for girls (cardiorespiratory endurance). These test items are reliable and valid instruments for measuring adolescents' physical fitness in China.

CRF was assessed by a $1000 \mathrm{~m} /$ boy and girl $800 \mathrm{~m} /$ girl run held during physical education classes in ] middle and high schools. The 1000 and $800 \mathrm{~m}$ runs were measured once to evaluate students' CRF. Students were required to maintain a steady pace and complete the task as quickly as possible. Safety and quality control during the measurements were highlighted. Participant performances in the CRF test were classified into one of four levels in terms of NSPFH 2014 in China. The participants with extreme CRF performances were classified either as performing poorly (i.e., a score of less than 60) or performing very well (i.e., a score of more than 90 ).

The main health-related MSF components are maximal strength (isometric and dynamic), explosive strength, endurance strength, and isokinetic strength. MSF was assessed by a standing-long jump test and pull ups/sit ups. In this study, we only employed the standing long jump test because many schools did not report the data of the pull up test. The standing broad jump test has been widely utilized for assessing explosive strength.

Health-related quality of life: HRQOL was measured using the Quality of Life Scale for Children and Adolescents (QLSCA), [35] a self-reported, generic measure of HRQOL validated for children and adolescents aged 7-18 years old. The QLSCA measures HRQOL in 13 dimensions: teacher and student relationship, student partnership, parent and children relationship, learning capability and attitude, self-perception, physical sense, negative moods and emotions, homework attitude, life convenience, social activities, sport capacity, self-satisfaction and others. The QLSCA items employed a five-point Likert-type scale to assess either frequency or intensity. The recall period was two weeks. Scores for each dimension were calculated and higher scores indicated better HRQOL. The Chinese version of the QLSCA has been found to have acceptable levels of reliability and validity [35]. 


\subsection{Statistical Analyses}

Descriptive statistics for gender, BMI, and CRF and MSF were calculated to characterize participants. The grade level for each student was coded as middle school (grades 6-8) or high school (grades 9-12). Both CRF and MSF were categorized using a score (poor $=<60$, fair $=60-74$, good $=75-89$, and excellent $=\geq 90$ ). The correlation analyses were performed to verify the potential linear associations among demographic characteristics, fitness, BMI, and quality of life. Analysis of covariance (ANCOVA) was performed with co-variable age to analyze differences of the QLSCA dimensions among categories of CRF, MSF, and BMI by gender. Multiple linear regression models were estimated to determine associations between physical fitness, BMI, and quality of life, with QLSCA dimensions as independent variables and age, gender, CRF and MFI, and BMI as dependent variables. Lastly, models with BMI, $\mathrm{CRF}$, and MFI were employed to analyze the independent effect of each variable. All values were expressed as the mean \pm standard deviation $(\mathrm{M} \pm \mathrm{SD})$ or frequency analysis numbers (percentage). The significance level was set at $p \leq 0.05$. All analyses were performed using SPSS 23.0 (IBM Corp., Armonk, NY, USA).

\section{Results}

The descriptive statistics for gender groups are presented in Table 1 . There was a higher percentage of overweightness or obesity in boys (19.4\%) than in girls (18.9\%). The mean CRF and MSF was $4.27 \pm 0.89$ and $4.22 \pm 0.89$, respectively, for the boys and $18.29 \pm 34.19$ and $186.40 \pm 33.30$, respectively, for the girls. Most of the items for each of the dimensions of QLSCA are similar between genders, except for self perception, social activity opportunity, sport capacity, and mean score, which are higher among boys.

Table 1. Descriptive Characteristics and Comparison.

\begin{tabular}{cccc}
\hline Variable & Boy $\mathbf{n}=\mathbf{5 2 7 6}$ & Girl $\mathbf{n}=4829$ & $p$ \\
\hline Age (years) & $14.14(1.79)$ & $14.22(1.81)$ & 0.459 \\
Height $(\mathrm{cm})$ & $165.35(9.24)$ & $161.90(8.40)$ & 0.043 \\
Weight $(\mathrm{kg})$ & $56.12 / 13.70$ & $55.63 / 12.61$ & 0.025 \\
BMI $\left(\mathrm{kg} / \mathrm{m}^{2}\right)$ & $20.44 / 4.45$ & $20.29 / 3.78$ & 0.481 \\
Overweightness/ obesity (/\%) & 19.4 & 18.9 & 0.435 \\
Cardiorespiratory fitness (1000/800 m) & $4.27 / 0.89$ & $4.22 / 0.89$ & 0.006 \\
Standing broad jump & $187.29 / 34.19$ & $186.40 / 33.30$ & 0.001 \\
QLSCA dimensions & & & \\
Teacher and student relationship & $146.33(37.16)$ & $146.40(36.40)$ & 0.931 \\
Student partnership & $159.59(34.40)$ & $159.63(33.98)$ & 0.955 \\
Parent and children relationship & $143.93(38.50)$ & $143.59(38.44)$ & 0.658 \\
Learning capacity and attitudes & $129.12(43.40)$ & $127.62(43.06)$ & 0.083 \\
Self-perception & $125.03(42.39)$ & $123.31(41.42)$ & 0.040 \\
Physical sense & $136.34(40.17)$ & $136.34(38.75)$ & 0.994 \\
Negative moods and emotion & $133.90(38.84)$ & $132.91(38.61)$ & 0.202 \\
Homework attitudes & $137.63(41.28)$ & $138.46(40.76)$ & 0.312 \\
Life convenience & $160.79(39.96)$ & $161.08(39.48)$ & 0.319 \\
Social activity opportunity & $130.98(40.61)$ & $129.14(39.44)$ & 0.022 \\
Sport capability & $140.94(39.31)$ & $137.08(38.61)$ & 0.000 \\
Self-satisfaction & $154.09(39.14)$ & $152.80(52.13)$ & 0.159 \\
Other & $144.08(33.99)$ & $144.04(34.88)$ & 0.951 \\
\hline
\end{tabular}

To examine the differences of QLSCA values amongst the different BMI, CRF, and MSF categories, ANCOVA was performed to verify whether QLSCA was worse in students with overweight/obesity and better in students with higher levels of physical fitness (Table 2). However, only several dimensions showed significant differences in this test. In boys, significant differences among BMI categories were found in physical sense $\left(\mathrm{F}(3,5204)=3.542, p=0.014, \eta^{2}=0.002\right)$, living convenience $(\mathrm{F}(3,5204)=4.462$, $\left.p=0.005, \eta^{2}=0.003\right)$, and self-satisfaction $\left(\mathrm{F}(3,5204)=3.498, p=0.015, \eta^{2}=0.002\right)$. In girls, significant 
differences in BMI were observed with different teacher and student relationships and social activity opportunities in this study. The parent and children relationship in boys $(\mathrm{F}(3,5204)=2.310, p=0.042$, $\left.\eta^{2}=0.002\right)$ and girls $\left(\mathrm{F}(3,5204)=1.786, p=0.013, \eta^{2}=0.008\right)$ are significantly different among levels of CRF. In boys, several dimensions showed significant differences in terms of MSF level, teacher and student relationship $\left(\mathrm{F}(3,5204)=4.384, p=0.002, \eta^{2}=0.003\right)$, student partnership $(\mathrm{F}(3,5204)=3.117$ $\left.p=0.014, \eta^{2}=0.002\right)$, parent and children relationship $\left(\mathrm{F}(3,5204)=4.195, p=0.002, \eta^{2}=0.003\right)$, physical sense $\left(\mathrm{F}(3,5204)=2.805, p=0.024, \eta^{2}=0.002\right)$, and negative moods and emotions $(\mathrm{F}(3,5204)=2.435$, $\left.p=0.045, \eta^{2}=0.002\right)$. The exception is student partnership $\left(\mathrm{F}(3,5204)=4.019, p=0.003, \eta^{2}=0.003\right)$ in girls.

Table 2. Analysis of Covariance of BMI, CRF, and MSF.

\begin{tabular}{|c|c|c|c|c|c|c|c|}
\hline Boy & & & & & & & \\
\hline BMI & UW & NW & OW & OB & $\mathrm{F}$ & $p$ & $\eta^{2}$ \\
\hline PS & $137.84 / 40.52$ & $135.05 / 40.01$ & $134.10 / 39.67$ & $138.73 / 39.89$ & 3.542 & 0.014 & 0.002 \\
\hline $\mathrm{LC}$ & $160.18 / 39.72$ & $159.84 / 40.80$ & $161.09 / 39.37$ & $166.45 / 37.10$ & 4.462 & 0.004 & 0.003 \\
\hline SS & $154.92 / 38.72$ & $153.01 / 39.85$ & $154.56 / 38.32$ & $158.82 / 37.82$ & 3.498 & 0.015 & 0.002 \\
\hline OT & $144.33 / 33.87$ & $142.94 / 34.32$ & $144.96 / 34.35$ & $147.38 / 32.49$ & 2.858 & 0.036 & 0.002 \\
\hline CRF & Poor & Fair & Good & Excellent & & & \\
\hline TSR & $147.87 / 37.35$ & $148.01 / 36.90$ & $145.04 / 37.53$ & $143.36 / 36.59$ & 3.17 & 0.007 & 0.003 \\
\hline PCR & $145.45 / 37.57$ & $145.00 / 39.05$ & $142.96 / 36.68$ & $141.50 / 37.97$ & 2.31 & 0.042 & 0.002 \\
\hline SAO & $131.52 / 40.15$ & $130.55 / 40.97$ & $130.36 / 40.12$ & $131.54 / 40.92$ & 3.657 & 0.004 & 0.003 \\
\hline MSF & Poor & Fair & Good & Excellent & & & \\
\hline TSR & $148.96(36.66)$ & $143.95(38.27)$ & $146.82(26.10)$ & $148.42(36.54)$ & 4.384 & 0.002 & 0.003 \\
\hline SP & $161.18(32.58)$ & $158.03(35.55)$ & $158.95(34.72)$ & $162.62(32.65)$ & 3.117 & 0.014 & 0.002 \\
\hline PCR & $147.18(37.64)$ & 141.44 (39.78) & $144.48(37.26)$ & $145.51(38.19)$ & 4.195 & 0.002 & 0.003 \\
\hline PS & $133.05(42.18)$ & $136.32(40.42)$ & $136.51(39.27)$ & $139.01(39.13)$ & 2.805 & 0.024 & 0.002 \\
\hline NME & $130.66(39.12)$ & $134.15(38.98)$ & $133.81(38.42)$ & $136.33(38.80)$ & 2.435 & 0.045 & 0.002 \\
\hline \multicolumn{8}{|l|}{ Girl } \\
\hline BMI & UW & NW & OW & OB & & & \\
\hline TSR & $147.07 / 36.95$ & $146.86 / 35.61$ & $146.77 / 35.98$ & $142.21 / 37.95$ & 2.076 & 0.004 & 0.007 \\
\hline SAO & $129.63 / 40.97$ & $130.58 / 38.16$ & $125.31 / 38.58$ & $124.31 / 39.93$ & 3.504 & 0.007 & 0.003 \\
\hline $\mathrm{CRF}$ & Poor & Fair & Good & Excellent & & & \\
\hline PCR & $145.55 / 37.22$ & $145.55 / 37.22$ & $142.38(38.28)$ & $141.29(40.13)$ & 1.786 & 0.013 & 0.008 \\
\hline LCA & $128.53 / 43.66$ & $127.87 / 42.92$ & $126.84 / 37.79$ & $124.28 / 43.86$ & 1.629 & 0.032 & 0.007 \\
\hline S-P & $123.93 / 42.43$ & $123.34 / 40.79$ & $124.81 / 37.65$ & $120.22 / 43.16$ & 2.173 & 0.001 & 0.01 \\
\hline OT & $143.97 / 37.85$ & $145.09 / 33.11$ & $139.32 / 39.01$ & $143.16 / 34.61$ & 1.64 & 0.03 & 0.008 \\
\hline MSF & Poor & Fair & Good & Excellent & & & \\
\hline SP & $157.37(36.07)$ & $159.15(33.65)$ & $160.29(33.43)$ & $161.68(33.25)$ & 4.019 & 0.003 & 0.003 \\
\hline
\end{tabular}

TSR: teacher and student relationship; SP: student partnership; PCR: parent and children relationship; LCA: learning capability and attitude; S-P: self-perception; PS: physical sense; NME: negative moods and emotions; HA: homework attitude; LC: life convenience; SAO: social activities opportunity; SC: sport capacity; SS: self-satisfaction; OT: other.

BMI, CRF, and MSF were utilized as predictors of health-related quality of life (Table 3). The multiple regression model (1) controlling for age showed that BMI was significantly associated with social activity opportunities in boys $(\beta=-0.040, p=0.019)$ and girls $(\beta=-0.059, p=0.000)$. In boys, CRF was significantly associated with the teacher and student relationship ( $\beta=-0.080, p=0.000)$ and self-satisfaction ( $\beta=0.064, p=0.002)$, but MSF was only associated with physical sense $(\beta=-0.080$, $p=0.000)$. In girls, CRF was significantly linked with negative moods and emotions, physical sense, and the parent and children relationship, whereas MSF was linked with social activity opportunities and self-perception. The multiple regression model (2) demonstrated that the results with BMI are the same as those of the model (1) variables. In girls, CRF was significantly associated with self-perception, 
learning capacity and attitudes, and homework attitude, except for model (1) variables. MSF is associated with the teacher and student relationship in boys $(\beta=-0.034, p=0.013)$ and student partnership $(\beta=-0.042, p=0.016)$ in girls, except for model (1) variables.

Table 3. Relationships between BMI, Physical Fitness, and Quality of Life.

\begin{tabular}{|c|c|c|c|c|c|c|c|c|c|}
\hline \multicolumn{10}{|c|}{ Model 1} \\
\hline \multicolumn{3}{|c|}{ Boys } & \multicolumn{7}{|c|}{ Girl } \\
\hline & B & $\beta$ & $\mathrm{P}$ & & & B & $\beta$ & $\mathrm{P}$ & \\
\hline \multicolumn{10}{|l|}{ BMI } \\
\hline LC & 0.001 & 0.063 & 0.000 & $F=5.464$ & SAO & -0.001 & -0.059 & 0.000 & $F=4.742$ \\
\hline SAO & -0.001 & -0.040 & 0.019 & $R^{2}=0.003$ & SS & 0.001 & 0.036 & 0.029 & $R^{2}=0.003$ \\
\hline \multicolumn{10}{|l|}{ CRF } \\
\hline TSR & -002 & -0.080 & 0.000 & $F=7.384$ & NME & 0.006 & 0.114 & 0.000 & $F=9.759$ \\
\hline \multirow[t]{2}{*}{ SS } & 0.002 & 0.064 & 0.002 & $R^{2}=0.005$ & PS & -0.004 & -0.076 & 0.000 & $R^{2}=0.007$ \\
\hline & & & & & PCR & 0.003 & 0.047 & 0.002 & \\
\hline \multicolumn{10}{|l|}{ MSF } \\
\hline \multirow[t]{2}{*}{ PS } & 0.001 & 0.040 & 0.004 & $F=8.236$ & SAO & 0.001 & 0.042 & 0.010 & $F=5.222$ \\
\hline & & & & $R^{2}=0.002$ & S-P & 0.001 & 0.037 & 0.022 & $R^{2}=0.004$ \\
\hline \multicolumn{10}{|c|}{ Model 2} \\
\hline \multicolumn{3}{|c|}{ Boys } & \multicolumn{7}{|c|}{ Girl } \\
\hline & B & $\beta$ & $\mathrm{P}$ & & & B & $\beta$ & $\mathrm{P}$ & \\
\hline \multicolumn{10}{|l|}{ BMI } \\
\hline $\mathrm{LC}$ & 0.001 & 0.060 & 0.000 & $F=5.151$ & SAO & -0.001 & -0.052 & 0.002 & $F=4.991$ \\
\hline SAO & 0.000 & -0.039 & 0.023 & $R^{2}=0.018$ & SS & 0.001 & 0.037 & 0.025 & $R^{2}=0.024$ \\
\hline \multicolumn{10}{|l|}{ CRF } \\
\hline TSR & -0.002 & -0.086 & 0.000 & $F=7.308$ & NME & 0.005 & 0.088 & 0.000 & $F=4.116$ \\
\hline PS & -0.001 & -0.041 & 0.004 & $R^{2}=0.067$ & PS & -0.005 & -0.092 & 0.000 & $R^{2}=0.032$ \\
\hline \multirow[t]{4}{*}{ SS } & 0.001 & 0.046 & 0.007 & & S-P & 0.004 & 0.077 & 0.004 & \\
\hline & & & & & LCA & -0.003 & -0.073 & 0.004 & \\
\hline & & & & & HA & 0.003 & 0.053 & 0.030 & \\
\hline & & & & & PCR & 0.002 & 0.045 & 0.043 & \\
\hline \multicolumn{10}{|l|}{ MSF } \\
\hline PS & 0.001 & 0.049 & 0.000 & $F=6.761$ & & & & & \\
\hline TSR & 0.001 & 0.036 & 0.009 & $R^{2}=0.059$ & & & & & \\
\hline
\end{tabular}

Model 1 controlled for age. Model 2 further adjusted for CRF and MSF to BMI, for BMI and MSF to CRF, and BMI and CRF to MSF.

\section{Discussion}

The purpose of the present study is to examine the impact of overweightness/obesity and physical fitness on the health-related quality of life in Chinese adolescents. A secondary purpose was to assess whether Chinese adolescents' BMI, CRF, and MSF can predict their HRQOL. The results suggested that BMI and CRF were associated with Chinese adolescents' HRQOL, which is in line with the hypothesis of this study. Results also indicated that the level of the HRQOL was generally low, and a lower level of HRQOL was found in overweight and obese individuals. Most of the dimensions of QLSCA showed no statistically significant differences in this study.

From overweightness and obesity perspectives, previous studies presented evidence that overweightness/obesity were negatively associated with several aspects of adults' HRQOL [36] and, thus, could impact the RQOL of children and adolescents, mainly in social, emotional, school, and physical dimensions of HRQOL $[10,37,38]$. In accordance with those findings, our study suggested that there were significant differences in terms of physical sense, living convenience, and self-satisfaction among boys with different weight status categories. In girls, there were significant differences in teacher and student relationships and social activity opportunities, however, no other dimensions of HRQOL 
were influenced significantly by BMI categories. A multiple regression analysis was employed to further analyze the impact of BMI on quality of life. The results showed that weight status significantly influenced social activity opportunity in both boys and girls.

The results are also partially consistent with those of a European KIDSCREEN research [39]. However, some studies did not find the effect of body weight on HRQOL. For instance, Kruger et al reported that their study did not reveal a significant relationship between BMI and QOL [40]. A higher BMI level was not associated with quality of life, but body weight increased with declining physical fitness and health conditions [41]. BMI and body fat were significantly associated with sports practice and good quality of sleep [42]. The results from different studies may illustrate that comparisons were different between BMI categories because overweightness and obesity were combined into a single category. Furthermore, it is possible these results were affected by differences in sample size, gender, age, and the range of BMI used.

No studies so far have utilized QLSCA to evaluate the association between CRF and HRQOL in large population-based samples of adolescents in China. Our study revealed that CRF is associated with the dimensions of the teacher and student relationship and self-satisfaction in boys; the CRF in girls was associated with the dimensions of the parent and children relationship, learning capacity and attitudes, and self-perception. These findings support our beliefs that teacher and parent support and concern are essential components that could affect adolescents' HRQOL. These results differed with previous studies, but it is reasonable to suggest that teacher and parent support can significantly influence participation in school-based physical activity. In China, high school teachers and parents do not encourage students to participate in physical activities because they believe that physical activity participation will sacrifice time for study thus affect academic performance. Meanwhile, most secondary school teachers do not pay attention to physical activity but emphasize students' academic performance due to the school requirements on academic achievement and competitiveness amongst schools $[43,44]$, even though there are studies that show that higher levels of physical fitness are beneficial to academic performance $[45,46]$. These may be plausible explanations as to why learning capacity and attitudes are more closely associated with HRQOL in girls.

It has been documented that CRF was positively associated with both physical well-being and emotional components of HRQOL in adults [47,48]. Improvements in CRF can lead to positive change on the mental health of children and adolescents [29]. Morales et al. [49] reported CRF is associated with physical well-being and social support and peers among boys and is associated physical well-being, self-perception, and social acceptance in girls. A positive association existed between CRF and waist-to-height, resting heart rate, and moderate to vigorous physical activity MVPA [50]. In this study, our results are partially consistent with social support in boys and self-perception in girls. However, a few researchers examined the associations between CRF and HRQOL, which warrants further study in this area.

Some studies found that MSF was associated with social acceptance and social support [44] and could promote the general health, psychological, and physical components of HRQOL [41]. The present study revealed that the association between the MSF and HRQOL were particularly strong for the physical sense and teacher and student relationship in boys, as well as student partnership and self perception in girls. This result is partially consistent with the findings of previous studies that observed associations between MSF and physical HRQOL dimensions, but has not observed associations between MSF and mental health dimensions [26,48]. This result demonstrated that MSF has a slight impact on the HRQOL of girls and boys. However, the present study exposed gender differences in HRQOL dimensions that are linked with MSF because it is probably more important for girls in psychological and emotional dimensions [17]. Gender differences in the impact of MSF on HRQOL could be attributed to differences in needs of explosive and endurance strength, which require exercises and sports in which adolescents participate in all the dimensions.

This study examined the associations between BMI, CRF, and MSF, and HRQOL. In boys-with BMI, CRF, and MSF in the model, while controlling for age- the association of CRF or overweightness 
with the HRQOL was stronger than that of MSF. CRF was more closely associated with HRQOL than BMI and MSF in girls. The results showed that, in girls, CRF has a significant impact on physical sense, negative moods, and emotion and self-perception. This study supported previous findings that low levels of physical fitness in children and adolescents results in reduced self-esteem [45,46], increased depression [51,52] and anxiousness [53,54], and lower HRQOL for the bullying dimension [39]. Sloan and Sawada (2009) verified the associations between CRF and HRQOL in young males and found a positive relationship between fitness levels and mental and physical components of HRQOL. One study analyzed the relationship of overweightness/obesity, CRF, and MSF on HRQOL in older people. It found that physical fitness affected physical health HRQOL subscales [26].

Our study found that both boys' and girls' BMIs were significantly associated with social activity component of HRQOL, which illustrated that overweightness and obesity may hamper their social activity and further affect education, learning, and working opportunities in China. CRF and MSF are crucial parts of HRQOL, however, we believe that learning capacity and achievement are more important components affecting student HRQOL than physical fitness levels in China.

This study has several strengths. First, it is the seminal study using the QLSCA that assessed the influences of PF and BMI on Chinese adolescents' HRQOL, exploring important but relatively unexplored Chinese adolescent HRQOL issues. Second, this study was established on a well-verified instrument, thus contributing to the reliability and validity of this approach in the context of physical fitness and QLSCA for Chinese students. Third, this study employed a random, large, and population-based sample of 80 public schools to elucidate the influences of BMI and physical fitness indictors associated with HRQOL among Chinese adolescents. Random large sampling allows us to better determine mean values and outliers, provide required precision, and avoid errors in this study. Finally, this study is a combination of self-reports and objective measures that involves various domains of CRF, MSF, and QLSCA.

This study has some limitations that may influence the generalizability of its outcome. First, this study utilized a cross-sectional design that prevents us from making causal inference. Future longitudinal research is needed to better understand how BMI and physical fitness affects HRQOL over time. Second, generalizations could be limited based on our outcome because of the use of the QLSCA in this study, which is deficient in accounting for chronic illness or comorbidities that are significantly associated with both overweightness/obesity, physical fitness, and HRQOL. Finally, it is noticed that epigenetic influences on both overweightness/obesity and physical fitness cannot be controlled in this study.

\section{Conclusions}

This study provides an initial approach using the Chinese version of QLSCA to examine the influences of physical fitness and BMI on Chinese adolescents' HRQOL. The findings of this study showed that overweightness and obesity significantly influence social activities and self-perception dimensions of HRQOL, but CRF and MSF are significantly associated with some dimensions of HRQOL. This study partially supports previous research using the European HRQOL. The importance of physical fitness was still supported by our findings that most of the students with good and excellent levels of physical fitness had a higher level of HRQOL. Our results suggest that exercise programs need to be well-designed by school administration in terms of educational systems, supervising overweightness and obesity, enforcing physical activity, and enhancing levels of physical fitness, which could be effective in improving adolescents' HRQOL in China.

Author Contributions: Y.F. and X.Y. conceived and designed the research; M.D. and X.Y. collected the data; X.Y. and R.B. analyzed the data; and Y.F. and X.Y. wrote the paper.

Funding: This research was funded by the Ministry of Science and Technology of China (2015FY111600).

Acknowledgments: This work was supported by 2015FY111600 from the Ministry of Science and Technology of China. We would like to thank all the subjects who participated in the study. 
Conflicts of Interest: The authors declare no conflict of interests.

\section{References}

1. Research Group on Chinese Students' Physical Fitness and Health. National survey on students' physical fitness and health in 2010. Chin. J. Sch. Health 2011, 32, 1026.

2. National Health and Family Planning Commission of the PRC. Nutrition and Chronic Disease Status of Chinese Residents. Available online: http://en.nhfpc.gov.cn/2015-06/15/c_45788_2.htm (accessed on 15 June 2015).

3. Oliva-Moreno, J.; Gil-Lacruz, A. Body weight and health-related quality of life in Catalonia, Spain. Eur. J. Health Econ. 2013, 14, 95-105. [CrossRef]

4. Takahashi, Y.S.M.; Tokuda, Y.; Takahashi, O.; Ohde, S.; Nakayama, T.; Fukuhara, S.; Fukui, T.; Shimbo, T. The relation between self-reported body weight and health-related quality of life: A cross-sectional study in Japan. J. Public Health 2011, 33, 518-526. [CrossRef]

5. McGavock, J.M.; Torrance, B.D.; McGuire, K.A.; Wozny, P.D.; Lewanczuk, R.Z. Cardiorespiratory fitness and the risk of overweight in youth: The healthy hearts longitudinal study of cardiometabolic health. Obesity 2009, 17, 1802-1807. [CrossRef]

6. Dey, M.; Gmel, G.; Mohler-Kuo, M. Body mass index and health-related quality of life among young Swiss men. BMC Public Health 2013, 13, 1028. [CrossRef]

7. Tsiros, M.D.; Olds, T.; Buckley, J.D.; Grimshaw, P.; Brennan, L.; Walkley, J.; Hills, A.P.; Howe, P.R.; Coates, A.M. Health-related quality of life in obese children and adolescents. Int. J. Obes. 2009, 33, 387-400. [CrossRef]

8. Farhat, T.; Iannotti, R.J.; Simons-Morton, B.G. Overweight, obesity, youth, and health-risk behaviors. Am. J. Prev. Med. 2010, 38, 258-267. [CrossRef]

9. Keating, C.L.; Moodie, M.L.; Swinburn, B.A. The health-related quality of life of overweight and obese adolescents-A study measuring body mass index and adolescent-reported perceptions. Int. J. Pediatr. Obes. 2011, 6, 434-441. [CrossRef]

10. Morales, P.F.; Sanchez-Lopez, M.; Moya-Martinez, P.; Garcia-Prieto, J.C.; Martinez-Andres, M.; Garcia, N.L.; Martinez-Vizcaino, V. Health-related quality of life, obesity, and fitness in schoolchildren: The cuenca study. Qual. Life Res. 2013, 22, 1515-1523. [CrossRef]

11. Griffiths, L.J.; Parsons, T.J.; Hill, A.J. Self-esteem and quality of life in obese children and adolescents: A systematic review. Int. J. Pediatr. Obes. 2010, 5, 282-304. [CrossRef]

12. Cameron, A.J.; Magliano, D.J.; Dunstan, D.W.; Zimmet, P.Z.; Hesketh, K.; Peeters, A.; Shaw, J.E. A bi-directional relationship between obesity and health-related quality of life: Evidence from the longitudinal aus diab study. Int. J. Obes. 2012, 36, 295-303. [CrossRef]

13. Petersen, S.; Moodie, M.; Mavoa, H.; Waqa, G.; Goundar, R.; Swinburn, B. Relationship between overweight and health-related quality of life in secondary school children in Fiji: Results from a cross-sectional population-based study. Int. J. Obes. 2014, 38, 539-546. [CrossRef]

14. Hamzaid, H.; Talib, R.A.; Azizi, N.H.; Maamor, N.; Reilly, J.J.; Wafa, S.W. Quality of life of obese children in Malaysia. Int. J. Pediatr. Obes. 2011, 6, 450-454. [CrossRef]

15. Bolton, K.; Kremer, P.; Rossthorn, N.; Moodie, M.; Gibbs, L.; Waters, E.; de Silva, A. The effect of gender and age on the association between weight status and health-related quality of life in Australian adolescents. BMC Public Health 2014, 14, 898. [CrossRef]

16. Helseth, S.; Haraldstad, K.; Christophersen, K.A. A cross-sectional study of health related quality of life and body mass index in a Norwegian school sample (8-18 years): A comparison of child and parent perspectives. Health Qual. Life Outcomes 2015, 13, 47. [CrossRef]

17. Michel, G.; Bisegger, C.; Fuhr, D.C.; Abel, T.; KIDSCREEN group. Age and gender differences in health-related quality of life of children and adolescents in Europe: A multilevel analysis. Qual. Life Res. 2009, 18, 1147-1157. [CrossRef]

18. Bovet, P.; Chiolero, A.; Shamlaye, C.; Paccaud, F. Prevalence of overweight in the Seychelles: 15 year trends and association with socio-economic status. Obes. Rev. 2008, 9, 511-517. [CrossRef]

19. Kim, H.S.; Park, J.; Ma, Y.; Ham, O.K. Factors influencing health-related quality of life of overweight and obese children in South Korea. J. Sch. Nurs. 2013, 29, 361-369. [CrossRef]

20. Low, L.C. Childhood obesity in developing countries. World J. Pediatr. 2010, 6, 197-199. [CrossRef] 
21. He, Q.Q.; Wong, T.W.; Du, L.; Jiang, Z.Q.; Yu TS, I.; Qiu, H.; Wu, J.G. Physical activity, cardiorespiratory fitness, and obesity among Chinese children. Prev. Med. 2011, 52, 109-113. [CrossRef]

22. Grontved, A.; Ried-Larsen, M.; Moller, N.C.; Kristensen, P.L.; Froberg, K.; Brage, S.; Andersen, L.B. Muscle strength in youth and cardiovascular risk in young adulthood (the European Youth Heart Study). Br. J. Sports Med. 2015, 49, 90-94. [CrossRef]

23. Ostojic, S.M.; Stojanovic, M.D.; Stojanovic, V.; Maric, J.; Njaradi, N. Correlation between fitness and fatness in 6-14-year old Serbian school children. J. Health Popul. Nutr. 2011, 29, 53-60. [CrossRef]

24. Rauner, A.; Mess, F.; Woll, A. The relationship between physical activity, physical fitness and overweight in adolescents: A systematic review of studies published in or after 2000. BMC Pediatrics 2013, 13, 19. [CrossRef]

25. Pedrero-Chamizo, R.; Gomez-Cabello, A.; Melendez, A.; Vila-Maldonado, S.; Espino, L.; Gusi, N.; Villa, G.; Casajus, J.A.; Gonzalez-Gross, M.; Ara, I. Higher levels of physical fitness are associated with a reduced risk of suffering sarcopenic obesity and better perceived health among the elderly: The EXERNET multi-center study. J. Nutr. Health Aging 2015, 19, 211-217. [CrossRef]

26. Wanderley, F.A.; Silva, G.; Marques, E.; Oliveira, J.; Mota, J.; Carvalho, J. Associations between objectively assessed physical activity levels and fitness and self-reported health-related quality of life in community-dwelling older adults. Qual. Life Res. 2011, 20, 1371-1378. [CrossRef]

27. Olivares, P.R.; Gusi, N.; Prieto, J.; Hernandez-Mocholi, M.A. Fitness and health-related quality of life dimensions in community-dwelling middle aged and older adults. Health Qual. Life Outcomes 2011, 9, 117. [CrossRef]

28. Ortega, F.B.; Ruiz, J.R.; Castillo, M.J.; Sjostrom, M. Physical fitness in childhood and adolescence: A powerful marker of health. Int. J. Obes. 2008, 32, 1-11. [CrossRef]

29. Ortega, F.B.; Artero, E.G.; Ruiz, J.R.; España-Romero, V.; Jiménez-Pavón, D.; Vicente-Rodríguez, G.; Ciarapica, D. Physical fitness levels among European adolescents: The HELENA study. Br. J. Sports Med. 2011, 45, 20-29. [CrossRef]

30. Padilla-Moledo, C.; Castro-Pinero, J.; Ortega, F.B.; Mora, J.; Marquez, S.; Sjostrom, M.; Ruiz, J.R. Positive health, cardiorespiratory fitness and fatness in children and adolescents. Eur. J. Public Health 2012, 22, $52-56$. [CrossRef]

31. Bonhauser, M.; Fernandez, G.; Puschel, K.; Yanez, F.; Montero, J.; Thompson, B.; Coronado, G. Improving physical fitness and emotional well-being in adolescents of low socioeconomic status in Chile: Results of a school-based controlled trial. Health Promot. Int. 2005, 20, 113-122. [CrossRef]

32. Chan, C.M.; Wang, W.C. Quality of life in overweight and obese young Chinese children: A mixed-method study. Health Qual. Life Outcomes 2013, 11, 33. [CrossRef]

33. Chen, Y.P.; Wang, H.M.; Edwards, T.C.; Wang, T.; Jiang, X.Y.; Lv, Y.R.; Patrick, D.L. Factors influencing quality of life of obese students in Hangzhou, China. PLoS ONE 2015, 10, e0121144. [CrossRef]

34. Ministry of Education (MOE) of the People's Republic of China. National Student's Physical Fitness and Health 2014. Available online: http://www.moe.gov.cn/s78/A17/twys_left/moe_943/moe_947/ (accessed on 17 June 2015).

35. Wu, H.R.; Meng, H. Reliability and validity of children and adolescents QQL scale. Chin. J. Sch. Health 2006, $27,18-21$.

36. Herman, K.M.; Hopman, W.M.; Craig, C.L. Are youth BMI and physical activity associated with better or worse than expected health-related quality of life in adulthood? The physical activity longitudinal study. Qual. Life Res. 2010, 19, 339-349. [CrossRef]

37. Wille, N.; Bullinger, M.; Holl, R.; Hoffmeister, U.; Mann, R.; Goldapp, C.; Reinehr, T.; Westenhofer, J.; Egmond-Froehlich, A.; Ravens-Sieberer, U. Health-related quality of life in overweight and obese youths: Results of a multicenter study. Health Qual. Life Outcomes 2010, 8, 36. [CrossRef]

38. Williams, J.W.; Canterford, L.; Hesketh, K.D.; Hardy, P.; Waters, L.B.; Patton, G.C.; Wake, M. Changes in body massindex and health related quality of life from childhood to adolescence. Int. J. Pediatr. Obes. 2011, 6, e442-e448. [CrossRef]

39. Ottova, V.; Erhart, M.; Rajmil, L.; Dettenborn-Betz, L.; Ravens-Sieberer, U. Overweight and its impact on the healthrelated quality of life in children and adolescents: Results from the European KIDSCREEN survey. Qual. Life Res. 2012, 21, 59-69. [CrossRef]

40. Rager, R.; Finegold, M.J. Cholestasis in immature newborn infants: Is parenteral alimentation responsible? J. Pediatr. 1975, 86, 264-269. [CrossRef] 
41. Hakkinen, A.; Rinne, M.; Vasankari, T.; Santtila, M.; Hakkinen, K.; Kyrolainen, H. Association of physical fitness with health-related quality of life in Finnish young men. Health Qual. Life Outcomes 2010, 8, 15. [CrossRef]

42. Carvalho, A.S.; Fernandes, A.P.; Gallego, A.B.; Vaz, J.A.; Vega, M.S. The relation of sports with sleep quality and anthropometric measures at secondary schools. J. Sport Health Res. 2019, 11, 91-106.

43. Xu, W.; Yao, L.; Lin, X.; Zhoy, K.; Dan, J.; Hou, F.; Yu, X. Constraints of school physical education reform and development: A grassroots investigation. J. Beijing Sport Univ. 2016, 8, 74-80.

44. Zhen, C.; Yi, X. Confirmatory factor analysis of the impact of dimension of integrated factors on the implementation of PE goals. J. Sports Sci. 2013, 3, 102-106.

45. Kramer, A.F.; Erickson, K.I.; Colcombe, S.J. Exercise, cognition and the aging brain. J. Appl. Physiol. 2006, 101, 1237-1242. [CrossRef]

46. Alghadir, A.H.; Gabr, S.A.; Iqbal, Z.A.; Al-Eisa, E. Association of physical activity, vitamin E levels, and total antioxidant capacity with academic performance and executive functions of adolescents. BMC Pediatr. 2019, 19, 156. [CrossRef]

47. Sloan, R.A.; Sawada, S.S.; Martin, C.K.; Church, T.; Blair, S.N. Associations between cardiorespiratory fitness and health-related quality of life health. Qual. Life Outcomes 2009, 7, 47. [CrossRef]

48. Garber, C.E.; Greaney, M.L.; Riebe, D.; Nigg, C.R.; Burbank, P.A.; Clark, P.G. Physical and mental health-related correlates of physical function in community dwelling older adults: A cross sectional study. BMC Geriatr. 2010, 10, 6. [CrossRef]

49. Morales, L.S.; Edwards, T.C.; Flores, Y.; Barr, L.; Patrick, D.L. Measurement properties of a multicultural weight-specific quality-of-life instrument for children and adolescents. Qual. Life Res. 2011, 20, $215-224$. [CrossRef]

50. O’Leary, M.; Rush, E.; Lacey, S.; Burns, C.; Coppinger, T. Cardiorespiratory fitness is positively associated with waist to height ratio and school socio economic status in Irish primary school aged children. J. Sport Health Res. 2018, 10, 389-402.

51. Eisenberg, M.E.; Neumark-Sztainer, D.; Haines, J.; Wall, M. Weight-teasing and emotional well-being in adolescents: Longitudinal findings from project EAT. J. Adolesc. Health 2006, 38, 675-683. [CrossRef]

52. Gibson, L.Y.; Byrne, S.M.; Blair, E.; Davis, E.A.; Jacoby, P.; Zubrick, S.R. Clustering of psychosocial symptoms in overweight children. Aust. N. Z. J. Psychiatry 2008, 42, 118-125. [CrossRef]

53. Storch, E.A.; Milsom, V.A.; Debraganza, N.; Lewin, A.B.; Geffken, G.R.; Silverstein, J.H. Peer victimization, psychosocial adjustment, and physical activity in overweight and at-risk-for-overweight youth. J. Pediatr. Psychol. 2007, 32, 80-89. [CrossRef] [PubMed]

54. Young-Hyman, D.; Tanofsky-Kraff, M.; Yanovski, S.Z.; Keil, M.; Cohen, M.L.; Peyrot, M.; Yanovski, J.A. Psychological status and weight-related distress in overweight or at-risk-for-overweight children. Obesity 2006, 14, 2249-2258. [CrossRef] [PubMed]

(C) 2019 by the authors. Licensee MDPI, Basel, Switzerland. This article is an open access article distributed under the terms and conditions of the Creative Commons Attribution (CC BY) license (http://creativecommons.org/licenses/by/4.0/). 